\title{
Enhanced biomethane production by co-digestion of mixed sewage sludge and dephenolised two-phase olive pomace
}

Waste Management \& Research

$1-10$

(c) The Author(s) 2021

Article reuse guidelines:

sagepub.com/journals-permissions DOI: 10.1177/0734242X211003979

journals.sagepub.com/home/wmr

@SAGE

\section{Rita Fragoso ${ }^{1}$ D, Ana Catarina Henriques², Javier Ochando-Pulido ${ }^{3}$, Nicole Smozinski² and Elizabeth Duarte ${ }^{1}$}

\begin{abstract}
In this study, co-digestion of mixed sewage sludge from a wastewater treatment plant (WWTP) and partially dephenolised twophase olive pomace (DOP) as a co-substrate was addressed with the aim of improving the biodigestibility of both substrates. The introduction of DOP into WWTP anaerobic digester facilities could significantly increase biomethane production and enhance the sustainability of both activities. An improvement in the system's performance was supported by stability parameters: total alkalinity increased and stabilised with the addition of $5 \% \mathrm{v} / \mathrm{v}$ DOP, and the specific energy loading rate was maintained at $0.177 \pm 0.03 \mathrm{~d}^{-1}$, which indicated better buffer capacity and stability in the bioreactor, and the possibility of enhancing the organic loading rate. In terms of average daily biogas production rate, an increase of $39 \%$ was achieved, up to $0.39 \pm 0.11 \mathrm{~L} \mathrm{~L}^{-1} \mathrm{~d}^{-1}$. Moreover, there was a $40 \%$ and $37 \%$ improvement in specific methane production and methane production rate, respectively, up to $0.28 \pm 0.02 \mathrm{~L} \mathrm{CH}_{4} \mathrm{~g}_{\mathrm{TVS}}{ }^{-1}$ and $0.26 \pm 0.08 \mathrm{~L} \mathrm{~L}^{-1} \mathrm{~d}^{-1}$. In addition, the proposed strategy leads to an energy saving of 20,328.6 $\mathrm{kWh}$ year-1 at the WWTP as a result of the electric energy production surplus, corresponding to an annual saving of $€ 3293.23$.
\end{abstract}

\section{Keywords}

Anaerobic co-digestion, biowaste management, dephenolised olive pomace, sewage sludge, phenols

Received 15th February 2021, accepted 1st March 2021 by Associate Editor Nemanja Stanisavljevic.

\section{Highlights}

- daily biogas production rate increased up to $39 \%$ with the addition of 5\% DOP as co-substrate;

- methane production and specific methane production rate increased by $40 \%$ and $37 \%$, respectively;

- a projected $20,328.6 \mathrm{kWh}$ year $^{-1}$ energy surplus at WWTPs as a result of the enhanced process;

- improved bioreactor stability supported by a better specific energy loading rate;

- sustainable strategy for Mediterranean countries where olive pomace (OP) is an important biowaste.

\section{Introduction}

At wastewater treatment plants (WWTPs), which are typically located in urban areas and operated and designed on the basis of bio-oxidation processes, a substantial portion of the potential chemical energy in wastewater streams in the form of carbon dioxide is unrecoverable. Moreover, to drive bio-oxidation of organic matter and ammonium and fulfil the legal requirements for effluent discharge, intensive energy input is needed. Furthermore, a huge amount of waste-activated sludge (WAS) is generated (Yang et al., 2019).

Under this framework WWTPs face a new paradigm that will have serious environmental and economic impacts, and anaerobic co-digestion of sewage sludge with other nutrient-rich substrates such as agrofood waste is a potential strategy that could be further explored to enhance energy recovery and nutrient balance (Pellera and Gidarakos, 2017). Such a strategy could improve the management of WWTPs and promote energy self-sufficiency (Zhang et al., 2014, 2017).

European Union (EU-28) policies concerning renewable energy systems set a fixed goal of supplying $32 \%$ of the European energy demand by 2030 . At least $25 \%$ of all bioenergy in the future is expected to come from anaerobic digestion/anaerobic co-digestion $(\mathrm{AD} / \mathrm{AcoD})$ of wet organic materials such as sewage sludge, whole crop silage and agrofood waste, among others (Kathijotes, 2016).

On the other hand, olive oil production is expanding worldwide because of the health-giving properties of olive oil. Based

1LEAF-Linking Landscape, Environment, Agriculture and FoodResearch Center, Instituto Superior de Agronomia, Universidade de Lisboa, Portugal

${ }^{2}$ Instituto Superior de Agronomia, University of Lisbon, Portugal ${ }^{3}$ Department of Chemical Engineering, University of Granada, Spain

\section{Corresponding author:}

Rita Fragoso, LEAF-Linking Landscape, Environment, Agriculture and Food-Research Center, Instituto Superior de Agronomia, Universidade de Lisboa, Tapada da Ajuda, 1349-017 Lisboa, Portugal. Email: ritafragosodisa.ulisboa.pt 
on FAOSTAT data, global olive production (FAO, 2019) was $20.9 \mathrm{~m}$ tons, which translates into $3.3 \mathrm{~m}$ tons of olive oil produced in the 2017-2018 season. In the EU-28, olive production was $12.9 \mathrm{~m}$ tons, which corresponds to $62 \%$ of the world's olive production. This translates into $2.2 \mathrm{~m}$ tons of olive oil, which represents $66 \%$ of the global olive oil production. It is remarkable that the four leading countries (Spain, Italy, Greece and Portugal) contribute to $99 \%$ of olive oil production in the EU-28 (EspadasAldana et al., 2019; IOC, 2018). The remaining olive oil production outside the EU-28 (34\%) is concentrated mainly in five countries: Morocco, Turkey, Tunisia, Syria and Algeria (FAO, 2019; IOC, 2018).

As a result of the olive oil sector activity, one of the most important and problematic biowastes in Mediterranean countries is generated. A huge amount of this is produced yearly during a short period (November-February) (Muscolo et al., 2019), thus causing serious management problems and causing a negative environmental impact, resource depletion and land degradation (Salome et al., 2015).

Two-phase olive oil milling is currently the most common technology used for olive oil production. It generates two types of olive biowaste: OP, also called olive mill solid waste (OMSW), and olive oil washing wastewater (OOWW) (Dermeche et al., 2013). Olive stones are very rich in lignocellulosic materials, and modern two-phase olive mills recover these from OP. The ratio of tons of OP to tons of olive oil is in the range 4:1 (Lama et al., 2017; Serrano et al., 2019). In the case of Spain, the largest producer, this amount is $2-2.5 \mathrm{~m}$ tons annually. The OP by-product is an excellent feedstock for biomass boilers, generating renewable energy for olive oil processing (Rodríguez et al., 2008). However, there are various reasons why the adoption of environmentally friendly approaches for the sustainable waste disposal of OP is difficult: small-scale mills are widely scattered; there is seasonal production only; the low price of the OP; limited storage life; and high transport costs (Caputo et al., 2003; Gunay and Karadak, 2015).

Suitable and sustainable treatment of OP is imperative because of its high organic load and humidity, low $\mathrm{pH}$ and the presence of inhibitory compounds such as polyphenols. Some solutions already proposed for the management of OP suggest it could be used for the absorption of heavy metals (Baccar et al., 2009; Bouzid et al., 2008; Malkoc et al., 2006), dyes (Akar et al., 2009) and phenols (Stasinakis et al., 2008), as well as composting (Haddadin et al., 2009) and biogas production (Tekin et al., 2000), among others.

One of the most promising technologies for the treatment of the biowaste generated from the olive oil extraction process is anaerobic digestion (AD), because of its potential to recover bioenergy (Battista et al., 2013). However, anaerobic degradation of olive mill wastes (OP and OOWW) presents some drawbacks in relation to the high amount of barely degradable cellulosic materials contained therein, low $\mathrm{pH}$ and the presence of toxic substances, mainly phenols, long-chain fatty acids and ethanol. These substances lead to a decrease in $\mathrm{pH}$ in the anaerobic reactor and, thus, can inhibit the activity of methanogenic archaea (Camarillo and Rincón, 2012).
Properly optimised co-digestion is necessary to increase microbial activity inside the digestor, enhancing the stability and performance of the process by supplying a carbon source and essential micronutrients (Gunay and Karadag, 2015). In this area, a number of studies have attempted the co-digestion of OP resulting from three-phase and two-phase production processes with several substrates. The following research should be highlighted: co-digestion with pig slurry (20\%) (Orive et al., 2016); with cattle manure digestate $(30 \% \mathrm{v} / \mathrm{v})$ pre-treated with hydrogen peroxide (Siciliano et al., 2016); with cotton gin, wine and juice industry wastes (Pellera and Gidarakos, 2017); with OOWW (10\% w/w) (Fezzani and Cheikh, 2010); and monodigestion of thermally pre-treated $\left(180 \mathrm{~min}\right.$ at $\left.120^{\circ} \mathrm{C}\right) \mathrm{OP}$ (Rincón et al., 2013).

In the present research work, a suitable management process for both OP generated in olive mills and mixed sewage sludge (MSS) from WWTPs is proposed. To this end, a series of benchscale experiments were conducted to compare the system response in terms of biogas and biomethane production yield with co-digestion of MSS and DOP, as compared with the monodigestion of MSS. Prior to this, the OP utilised has been pretreated for the extraction of high added-value polyphenols, which helps to revalorise the OP by-product from a material point of view and, subsequently, this process will facilitate its energy valorisation through the proposed anaerobic co-digestion process. The introduction of this by-product as a co-substrate in the anaerobic digestion of MSS may help enhance the circular bioeconomy target in both WWTPs and olive mills. This objective would be favoured in olive oil producing regions where small-scale mills are situated in the vicinity of WWTPs. To the authors' knowledge, there is no previous research work that has focused on the use of destoned and partially DOP as a co-substrate in the anaerobic co-digestion of MSS produced by urban WWTPs.

\section{Material and methods}

\section{Source of samples and pre-treatments}

Sewage sludge samples were collected from a WWTP located in Lisbon (Portugal) with a total treatment capacity of $50,000 \mathrm{~m}^{3} /$ day of wastewater mainly derived from municipal sources, which corresponds to 210,000 in terms of population equivalent (unit per capita loading). The sewage entering the plant undergoes grit removal before primary sedimentation (PS), followed by an activated sludge treatment process. The sludge from PS is thickened and then homogenised with WAS that has been previously thickened by dissolved air flotation. The MSS has an average proportion of $40 \%$ PS: $60 \%$ WAS (v/v).

OP samples were taken from an olive oil mill in the Andalusian province of Granada (Spain), one of the main olive and olive oil production regions worldwide. The mill from which the samples were taken operates with the most up-to-date two-phase olive oil production technology. Raw OP was taken in-situ directly from the exit of the horizontal centrifuges during the production process.

After collection, raw OP was readily subjected to phenol extraction with OOWW from the same olive mill, as shown in 

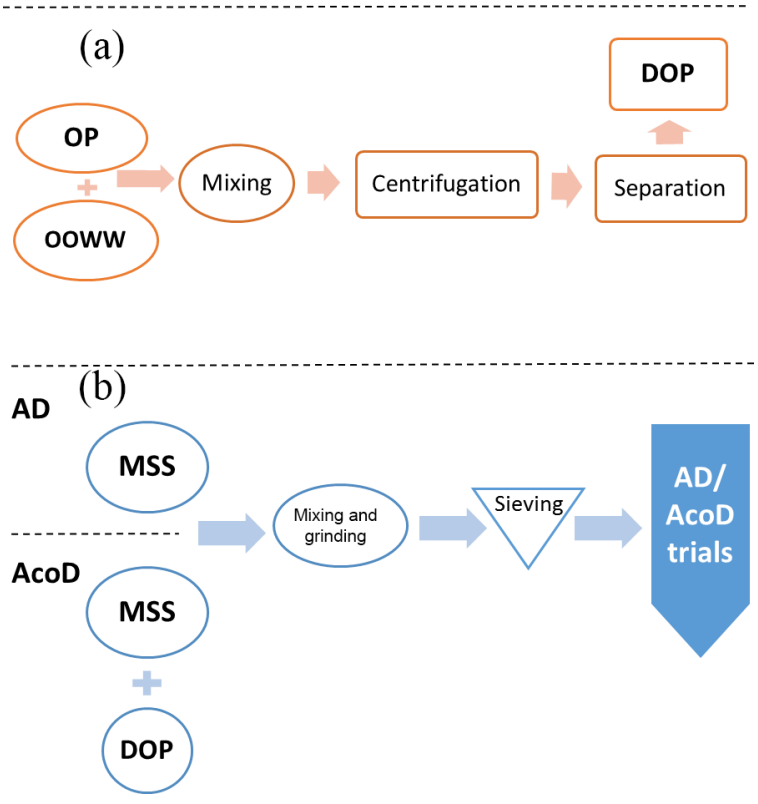

Figure 1. Pre-treatments given to substrates in the laboratory prior to experiments: preparation of partially dephenolised two-phase olive pomace (a) and of feed for anaerobic digestion/co-digestion trials (b).

DOP: dephenolised two-phase olive pomace; OP: olive pomace; OOWW: olive oil washing wastewater; MSS: mixed sewage sludge; $\mathrm{AD}$ : anaerobic digestion; AcoD: anaerobic co-digestion.

Figure 1(a), and described in former works by the authors (Ochando-Pulido et al., 2018). Briefly, OP samples were mixed $(1: 2 \mathrm{v} / \mathrm{v})$ with OOWW and homogenised for $1 \mathrm{~h}$ residence time under a low stirring rate (150-200 rpm) and ambient temperature to extract phenolic compounds from OP to OOWW; thereafter, solid/liquid separation was performed in a centrifuge $(1 \mathrm{~min}$, $3000 \mathrm{rpm})$. The centrifugal process generated three phases: an oily phase (1\%-2\%) on top; an aqueous phase enriched in polyphenols; and a solid phase, that is, partially dephenolised twophase olive pomace (DOP), at the bottom. Partially DOP was then stored under refrigeration $\left(4^{\circ} \mathrm{C}\right)$ to keep it stable for the downstream anaerobic co-digestion experiments with MSS (Figure 1(b)).

As described in Figure 1(b), to obtain a homogenous feed stream, the MSS (for AD trials) or a mixture of $5 \% \mathrm{v} / \mathrm{v}$ of DOP and MSS (for AcoD trials) was grinded with a mechanical blender $(\mathrm{P}=150 \mathrm{~W}, \mathrm{t}=2 \mathrm{~min}$ ), followed by sieving (mesh size of $2 \mathrm{~mm}$ ). This procedure aimed to avoid problems with clogging and prevent the formation of floating layers inside the digester.

\section{Physico-chemical characterisation}

The following parameters were determined in accordance with standard methods (Baird and Bridgewater, 2017) for MSS, DOP, feed mixtures and digestate samples: $\mathrm{pH}$; electrical conductivity (EC); mass density ( $\rho$ ); total solids and total volatile solids (TS, TVS); total suspended solids and volatile suspended solids (TSS, VSS); total chemical oxygen demand and soluble chemical oxygen demand (TCOD and SCOD); total alkalinity (TA); and total Kjeldahl nitrogen (TKN).
Table 1. Physico-chemical characterisation of raw mixed sewage sludge and partially dephenolised two-phase olive pomace used in the trials (Average $\pm S D ; n=10$ ).

\begin{tabular}{lcc}
\hline Parameters & MSS & DOP \\
\hline $\mathrm{pH}$ & $5.70 \pm 0.15$ & $5.35 \pm 0.12$ \\
$\mathrm{EC}\left(\mathrm{mS} \mathrm{cm}^{-1}\right)$ & $1.89 \pm 0.16$ & $1.84 \pm 0.14$ \\
$\rho\left(\mathrm{kg} \mathrm{m}^{-3}\right)$ & 1014 & 1785 \\
$\mathrm{TS}\left(\mathrm{g} \mathrm{L}^{-1}\right)$ & $17.43 \pm 1.05$ & $217.70 \pm 11$ \\
$\mathrm{TVS}\left(\mathrm{g} \mathrm{L}^{-1}\right)$ & $15.04 \pm 0.85$ & $209.39 \pm 21$ \\
TVS/TS (\%) & 86.30 & 96.18 \\
TCOD $\left(\mathrm{g} \mathrm{L}^{-1}\right)$ & $23.06 \pm 0.98$ & $256.22 \pm 23.22$ \\
SCOD $\left(\mathrm{g} \mathrm{L}^{-1}\right)$ & $2.36 \pm 0.14$ & $34.10 \pm 3.30$ \\
$\mathrm{SCOD} / \mathrm{TCOD}(\%)$ & 10.20 & 13.30 \\
TOC $\left(\mathrm{g} \mathrm{L}^{-1}\right)$ & $8.72 \pm 0.34$ & 121.46 \\
TKN $\left(\mathrm{g} \mathrm{L}^{-1}\right)$ & $1.23 \pm 0.16$ & 2.95 \\
$\mathrm{C} / \mathrm{N}$ & 7.0 & 42.0 \\
TPhs $(\mathrm{mg} \mathrm{GAE} \mathrm{L-1)}$ & 54.17 & 4220.77 \\
\hline
\end{tabular}

MSS: mixed sewage sludge; DOP partially dephenolised two-phase olive pomace; EC: electrical conductivity; $\rho$ : mass density; TS: total solids; TVS: total volatile solids; TCOD: total chemical oxygen demand; SCOD: soluble chemical oxygen demand; TOC: total organic carbon; TKN: total Kjeldahl nitrogen; $\mathrm{C} / \mathrm{N}$ : carbon-nitrogen ratio; TPhs: total phenols.

Total phenolic compounds concentration (TPhs, in $\mathrm{mgL}^{-1}$ of gallic acid equivalent (GAE)) was determined following the Folin-Cicolteau method (Greenberg et al., 2005). Total organic carbon (TOC) was calculated based on the method described by Cuetos et al. (2011). The $\mathrm{C} / \mathrm{N}$ (carbon-nitrogen) ratio was determined by dividing the TOC by the TKN values. All analytical determinations were performed in triplicate and with analytical grade reagents ( $\geqslant 99 \%$ purity).

The physico-chemical characterisations of raw MSS and DOP are reported in Table 1.

It is important to highlight that MSS presents a low $\mathrm{C} / \mathrm{N}$ proportion (below a ratio of 10) as well as low soluble COD content (SCOD/TCOD of about 10). These features indicate low availability of organic matter for anaerobic biodegradation, probably due to the presence of refractory materials. Although anaerobic biotechnology is considered an economic and sustainable solution for wastewater treatment, it carries certain constraints, because complex materials present in the sludge require longer retention times and larger digester volumes (Pinto et al., 2016; Raheem et al., 2018).

As can be seen in Table 1, DOP presents a $\mathrm{C} / \mathrm{N}$ ratio approximately six times higher than that of the MSS, which indicates that this by-product from olive oil industry could be a potential co-substrate for providing a more appropriate carbon to nutrient ratio in the feed blend improving the conversion process and methane yield (Hagos et al., 2017; Li et al., 2019). Moreover, there is a higher content in soluble organic matter (SCOD) in DOP than in MSS $\left(34.10 \pm 3.30\right.$ as opposed to $\left.2.36 \pm 14 \mathrm{~g} \mathrm{~L}^{-1}\right)$ or TVS (up to $209.39 \mathrm{~g} \mathrm{~L}^{-1}$ ). These are important characteristics of DOP as a co-substrate for MSS anaerobic treatment; solubilisation of particulate COD can be a critical aspect in AD because the microbial consortia require organic matter in soluble form.

The measured physico-chemical characteristics of the DOP used in this study are similar to those recently reported for 
high-temperature thermally dephenolised OP by Serrano et al. (2019), who attained TCOD and SCOD values only about 7\% lower as well as slightly lower $\mathrm{pH}$. In our case, as the extraction procedure of OP with OOWW is performed at ambient temperature, there is no additional energy consumption. TS and TVS values obtained for DOP are also in accordance with the data reported by Lama et al. (2017) for thermally pre-treated two-phase OP.

With regard to total phenols (TPhs), DOP presented $4220.77 \mathrm{mg} \mathrm{L}^{-1}$, a value lower than those reported by other authors (Alagoz et al., 2015; Serrano et al., 2017, 2019). This value is $44.6 \%$ below that of fresh OP, which was $7613.57 \mathrm{mg}$ $\mathrm{L}^{-1}$, thus $3392.8 \mathrm{mg} \mathrm{L}^{-1}$ total phenols were extracted from the pomace during pre-treatment. This value is significantly lower than the $10,000 \mathrm{mg} \mathrm{L}^{-1}$ reported by Maragkaki et al. (2017) as the limit above which TPhs concentration is considered highly inhibitory for microorganisms.

\section{Anaerobic mono-digestion vs co- digestion experiments}

The AD bench-scale unit used in this study consisted of a semicontinuously stirred tank reactor (CSTR) with $16 \mathrm{~L}$ total volume and $11.3 \mathrm{~L}$ working volume. The system was provided with a feed pump (Watson Marlow - 60 rpm), an electric blade stirrer (Velp Scientifica ES overhead stirrer) and an external jacket coupled with a thermostat and thermal blanket with an accuracy of $\pm 0.5^{\circ} \mathrm{C}$, which served to keep the temperature range at $35.5 \pm 1.8^{\circ} \mathrm{C}$. In addition, the biogas volume production rate was measured by a gas flow meter (Ritter Milligas counter), whereas the composition of the biogas stream obtained $-\% \mathrm{v} / \mathrm{v}$ of methane $\left(\mathrm{CH}_{4}\right)$, carbon dioxide $\left(\mathrm{CO}_{2}\right)$ and nitrogen $\left(\mathrm{N}_{2}\right)$, as well as hydrogen sulphide $\left(\mathrm{H}_{2} \mathrm{~S}\right)$ in ppm - was provided by a portable biogas quality analyser (LMSxi multifunction landfill gas analyser), with an accuracy of $\pm 3 \%$ and a detection range for $\mathrm{H}_{2} \mathrm{~S}$ of between 200 and $1500 \mathrm{ppm}$.

To compare the effect of the addition of DOP on the anaerobic bioreactor performance in terms of biogas and biomethane production, the experimental procedure comprised two main phases that were performed consecutively: first, AD with $100 \%$ MSS as feedstock (reference scenario); thereafter, AcoD using a feed mixture of $95: 5 \mathrm{v} / \mathrm{v}$ of MSS:DOP.

The AD phase, after achieving steady state conditions, comprised two complete operating cycles. Once this phase was completed, AcoD with DOP was initiated and conducted for three consecutive runs. The first AcoD cycle served to observe the effect of the addition of DOP on the performance of the bioreactor through the gas production rate. Following the kinetic curve profile, the steady state condition was assumed when the daily average gas production rate varied less than $5 \%$. Two additional AcoD cycles were carried out to observe the evolution of the system's performance, thus allowing the comparison with the AD trial.

The total monitoring period of the study was 85 days, corresponding to 5 cycles, with a hydraulic retention time (HRT) of 17 days per cycle. During all the cycles, the temperature of the process was controlled and corrected by the heating system, which allowed the maintenance of appropriate mesophilic conditions $\left(35.5 \pm 1.8^{\circ} \mathrm{C}\right)$.

During the experimental period, inlet and outlet flow rates, reactor temperature and biogas production were measured daily (working days), whereas biogas quality was analysed once a week. The feed mixtures were fully monitored during the trials to control process performance, in terms of $\mathrm{pH}, \mathrm{EC}, \mathrm{TS}$, TVS, TCOD, SCOD, TKN, C/N and TPhs. The digestates were also characterised to determine the removal efficiencies and the digester stability. The operational parameters - organic loading rate (OLR), biogas production rate (GPR) and methane production rate (MPR), specific methane production (SMP), total alkalinity (TA) and specific energy loading rate (SELR) - were determined twice per cycle.

The SELR ( $\mathrm{g}_{\text {TCOD }} \mathrm{d}^{-1} \mathrm{~g}_{\mathrm{VSS}}{ }^{-1}$ ) refers to the ratio between the daily average fed organic load (expressed in TCOD) and the active biomass inside the reactor (expressed in VSS), according to equation (1) (Pinto et al., 2016), and can be considered as an indicator of food to mass ratio $(\mathrm{F} / \mathrm{M})$. It expresses the rate of the methanogenic bioconversion into biogas/biomethane.

$$
S E L R=Q \times[T C O D]_{\text {inlet }} /[V S S] \times V_{\text {working }}
$$

in which

$Q$ : inlet flow rate $\left(\mathrm{L} \mathrm{d}^{-1}\right)$

[TCOD]: feed total COD concentration $\left(\mathrm{g} \mathrm{L}^{-1}\right)$

[VSS]: digestate volatile suspended solids concentration $\left(\mathrm{g} \mathrm{L}^{-1}\right)$

$V_{\text {working: }}$ : working volume of the reactor (L)

where

$Q \times[T C O D]_{\text {inlet }}:$ feed organic load (expressed as TCOD)

[VSS] $\times V_{\text {working }}$ : mass of the biomass inside the reactor

\section{Benefits of changing from mono- digestion to co-digestion for electric energy production}

An estimation of electric energy production surplus $\left(\Delta \mathrm{E}_{\mathrm{p}}\right)$ resulting from the introduction of DOP as co-substrate as compared with MSS as a mono-substrate was performed based on a simplified approach. The energy consumption was considered to be the same in both scenarios.

The electric energy produced in each trial was determined based on the total biogas obtained and its methane content ( $\mathrm{v} / \mathrm{v}$ percentage). According to Singh and Basak (2018), one cubic metre of biogas containing $60 \%$ methane $(\mathrm{v} / \mathrm{v})$ on average, produces around $2 \mathrm{kWh}$ of electric energy. Given that the biogas produced in the developed mono- and co-digestion sets of experimental runs provided different methane concentrations, it was necessary to adjust the lower calorific value for each of the different trials. The calculations of $L C V_{\text {biogas }}$, based on the equations referenced in the literature by Von Mitzlaff (1988), were the following

$$
L C V_{\text {biogas }}=\times \rho_{\mathrm{CH} 4} \times L C V_{C H 4}
$$


Table 2. Digester input (feed streams) and output (digestate) characterisation.

\begin{tabular}{|c|c|c|c|c|}
\hline \multirow[t]{2}{*}{ Parameters } & \multicolumn{2}{|l|}{$A D$} & \multicolumn{2}{|l|}{$A c o D$} \\
\hline & Feed mixture & Digestate & Feed mixture & Digestate \\
\hline MSS:DOP (v/v) & $100: 0$ & $\mathrm{n} / \mathrm{a}$ & $95: 5$ & $\mathrm{n} / \mathrm{a}$ \\
\hline OLR (gvs $L_{\text {reactor }} d^{-1}$ ) & $0.90 \pm 0.02$ & $\mathrm{n} / \mathrm{a}$ & $0.94 \pm 0.06$ & $\mathrm{n} / \mathrm{a}$ \\
\hline $\mathrm{pH}$ & $5.59 \pm 0.31$ & $7.22 \pm 0.08$ & $5.31 \pm 0.23$ & $7.02 \pm 0.07$ \\
\hline $\mathrm{EC}\left(\mathrm{mS} \mathrm{cm}^{-1}\right)$ & $1.89 \pm 0.16$ & $4.60 \pm 0.20$ & $2.25 \pm 0.14$ & $4.14 \pm 0.15$ \\
\hline $\mathrm{TS}\left(g \mathrm{~L}^{-1}\right)$ & $17.43 \pm 0.90$ & 17.02 & $19.79 \pm 0.42$ & $15.57 \pm 0.23$ \\
\hline TVS (g $\left.L^{-1}\right)$ & $15.04 \pm 0.70$ & 12.38 & $17.60 \pm 0.38$ & $12.9 \pm 0.09$ \\
\hline TVS/TS (\%) & 86 & 73 & 89 & 83 \\
\hline $\operatorname{VSS}\left(g L^{-1}\right)$ & $\mathrm{n} / \mathrm{a}$ & 11.31 & $\mathrm{n} / \mathrm{a}$ & 11.25 \\
\hline $\operatorname{TCOD}\left(g \mathrm{~L}^{-1}\right)$ & $23.06 \pm 0.20$ & $20.01 \pm 0.20$ & $31.66 \pm 0.67$ & $18.19 \pm 1.74$ \\
\hline $\operatorname{SCOD}\left(g L^{-1}\right)$ & $2.36 \pm 0.10$ & $1.32 \pm 0.10$ & $4.08 \pm 0.98$ & $2.39 \pm 0.07$ \\
\hline SCOD/TCOD (\%) & 10 & $\mathrm{n} / \mathrm{a}$ & 13 & $\mathrm{n} / \mathrm{a}$ \\
\hline TOC $\left(g L^{-1}\right)$ & $8.72 \pm 0.34$ & & $10.21 \pm 0.36$ & \\
\hline $\operatorname{TKN}\left(g L^{-1}\right)$ & $1.23 \pm 0.16$ & & $0.96 \pm 0.12$ & \\
\hline $\mathrm{C} / \mathrm{N}$ & 7 & & 11 & \\
\hline TPhs (mg GAE L-1) & $54.17 \pm 10.00$ & 46.59 & $241.67 \pm 4.17$ & 179.17 \\
\hline
\end{tabular}

$A D$ : anaerobic digestion; AcoD: anaerobic co-digestion; MSS: mixed sewage sludge; DOP partially dephenolised two-phase olive pomace; OLR: organic loading rate; EC: electrical conductivity; TS: total solids; TVS: total volatile solids; VSS: volatile suspended solids; TCOD: total chemical oxygen demand; SCOD: soluble chemical oxygen demand; TOC: total organic carbon; TKN: total Kjeldahl nitrogen; C/N: carbon-nitrogen ratio; TPhs: total phenols.

Values correspond to average (Average $\pm \mathrm{SD} ; n=10$ ).

where

$L C V_{\text {Biogas }}$ : biogas low calorific value $\left(\mathrm{MJ} / \mathrm{Nm}^{3}\right)$

$C_{C H 4}$ : methane concentration $(\%, \mathrm{v} / \mathrm{v})$

$\rho_{C H 4}:$ methane specific weight $\left(0.72 \mathrm{~kg} / \mathrm{m}^{3}\right)$

$L C V_{C H 4}$ : methane low calorific value $(50 \mathrm{MJ} / \mathrm{kg})$

For each trial, the amount of specific electric energy potential

$\left(E_{\mathrm{P}}\right)$ was calculated according to the following equation

$$
\mathrm{E}_{\mathrm{P}}=\mathrm{LCV}_{\text {Biogas }} \mathrm{x} \eta \mathrm{x} \sigma
$$

where

$E_{P}$ : specific electric energy potential $\left(\mathrm{kWh} / \mathrm{kg}_{\mathrm{TVS}}\right)$

$L C V_{\text {Biogas }}$ : biogas low calorific value $\left(\mathrm{MJ} / \mathrm{Nm}^{3}\right)$

$\eta$ : biogas yield $\left(\mathrm{m}^{3} / \mathrm{kg}_{\mathrm{TVS}}\right)$

$\sigma$ : conversion factor of $\mathrm{MJ}$ to $\mathrm{kWh}(0.28)$

The specific $\Delta E_{p}\left(\mathrm{kWh} / \mathrm{kg}_{\mathrm{TVS}}\right)$ was calculated using equation (4), whereas the $\mathrm{E}_{\mathrm{P}}$ for $\mathrm{AD}$ and $\mathrm{AcoD}$ was calculated as described above using the biogas and biomethane yield obtained (Table 3).

$$
\Delta E_{p}\left(\mathrm{kWh} / \mathrm{kg}_{\mathrm{TVS}}\right)=\mathrm{E}_{\mathrm{P}}(\mathrm{AcoD})-\mathrm{E}_{\mathrm{P}}(\mathrm{AD})
$$

\section{Results and discussion}

\section{Bioreactor performance and stability during $A D$ vs AcoD trials}

The physico-chemical characteristics of the feed streams used in $\mathrm{AD}$ and $\mathrm{AcoD}$, and of the digestates obtained are summarised in Table 2 .

As can be observed in Table 2, the addition of 5\% (v/v) DOP per litre of MSS led to a slight increase (4.5\%) in the OLR of the
Table 3. Input and output operation parameters during anaerobic and anaerobic co-digestion experiments

\begin{tabular}{|c|c|c|}
\hline Parameters & $\mathrm{AD}(n=2)$ & $\operatorname{AcoD}(n=2)$ \\
\hline Temperature ${ }^{\circ} \mathrm{C}$ & $36.30 \pm 1.10$ & $35.10 \pm 1.40$ \\
\hline HRT (d) & 17 & 17 \\
\hline GPR $\left(L L^{-1} d^{-1}\right)$ & $0.28 \pm 0.10$ & $0.39 \pm 0.11$ \\
\hline $\operatorname{MPR}\left(L L^{-1} d^{-1}\right)$ & $0.19 \pm 0.08$ & $0.26 \pm 0.08$ \\
\hline $\operatorname{SGP}\left(\operatorname{Lg}_{\mathrm{TVS}^{-1}}{ }^{-1}\right.$ & $0.30 \pm 0.04$ & $0.42 \pm 0.07$ \\
\hline $\mathrm{SMP}\left(\mathrm{LCH}_{4} \mathrm{~g}_{\mathrm{TVs}}{ }^{-1}\right)$ & $0.20 \pm 0.03$ & $0.28 \pm 0.02$ \\
\hline TVS removal (\%) & 18 & 27 \\
\hline TCOD removal (\%) & $23.10 \pm 0.8$ & $42.54 \pm 0.6$ \\
\hline TPhs removal (\%) & 14.0 & 25.10 \\
\hline SELR $\left(d^{-1}\right)$ & $0.122 \pm 0.02$ & $0.177 \pm 0.03$ \\
\hline $\mathrm{TA}\left(\mathrm{gCaCO}_{3} \mathrm{~L}^{-1}\right)$ & $1.23 \pm 0.07$ & $2.22 \pm 0.04$ \\
\hline
\end{tabular}
(Average $\pm \mathrm{SD} ; n=10$ ).

AD: anaerobic digestion; AcoD anaerobic co-digestion; HRT: hydraulic retention time; GPR: biogas production rate; MPR: methane production rate; SGP: specific biogas production; SMP: specific methane production; TVS: total volatile solids; TCOD: total chemical oxygen demand; TPhs: total phenols; SELR: specific energy loading rate; TA: total alkalinity.

blend. Specifically, the OLR was set at $0.90 \pm 0.02 \mathrm{~g}_{\mathrm{TVS}} \mathrm{L}^{-1}$ reactor day $^{-1}$ during anaerobic mono-digestion experiments with MSS (lasting two complete cycles), whereas it was increased to $0.94 \pm 0.06 \mathrm{~g}_{\mathrm{TVS}} \mathrm{L}_{\text {reactor }}^{-1}$ day $^{-1}$ during AcoD runs when DOP was added. In any case, the established OLR value complied with the recommendation reported by various researchers that feeding the anaerobic digester at OLR higher than $1.00 \mathrm{~g}_{\mathrm{TVS}} \mathrm{L}^{-1}$ reactor . day ${ }^{-1}$ should be avoided (Battista et al., 2015; Serrano et al., 2019; Stoyanova et al., 2017).

As explained in section Material and Methods, the last two AcoD cycles were performed to examine the subsequent response 
(a)

(b)
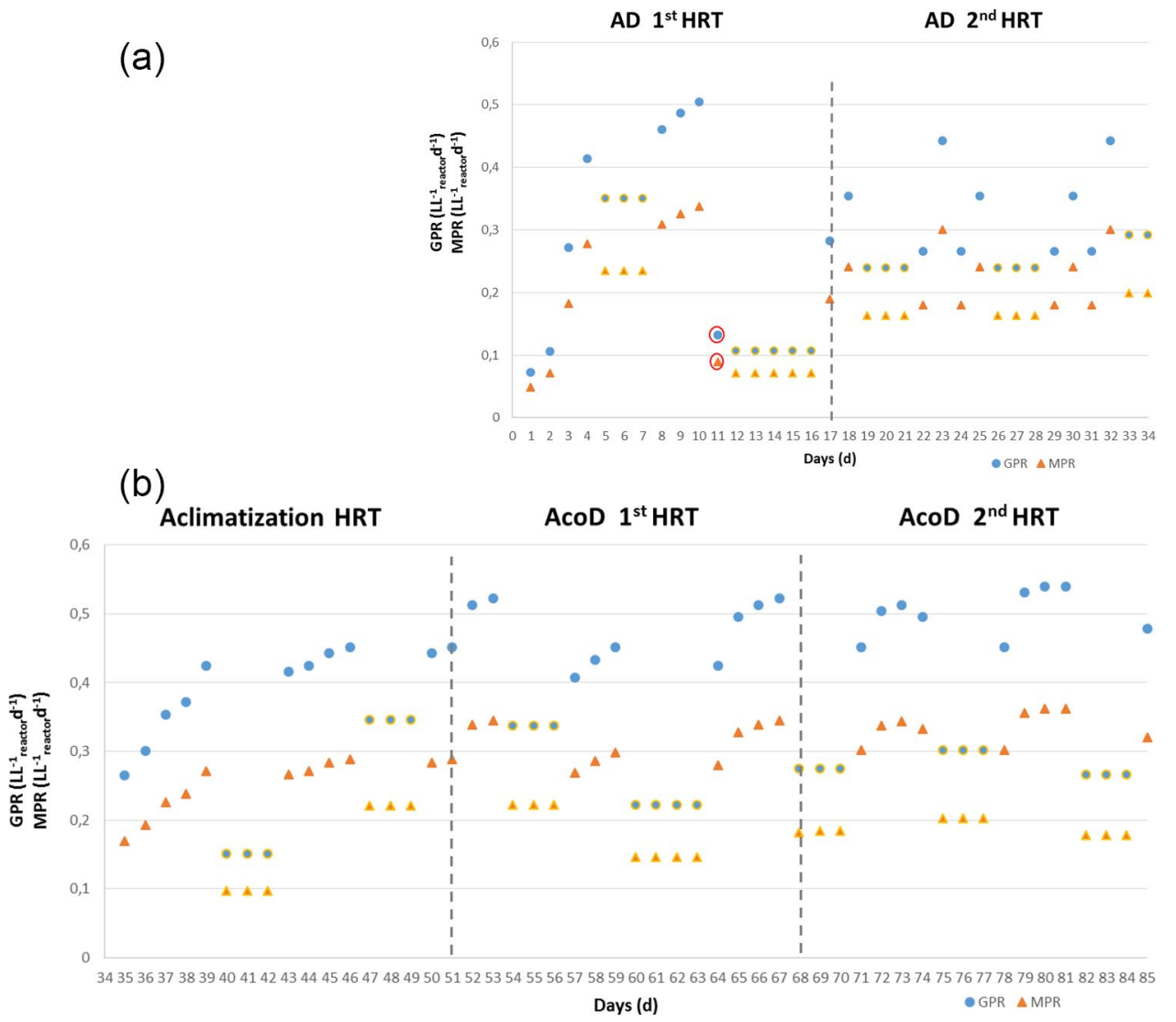

Figure 2. Biogas production rate and methane production rate during anaerobic digestion (a) and anaerobic co-digestion (b). The data points corresponding to non-feeding days have a yellow solid line around the marker. On the 11 th day a clogging event led to abnormal biogas and methane production rate values.

HRT: hydraulic retention time; GPR: biogas production rate; MPR: methane production rate.

of the system under the established conditions. Bioreactor performance was assessed based on biogas production and quality, along with digestate control parameters.

As a result of the addition of $5 \%(\mathrm{v} / \mathrm{v})$ DOP co-substrate to the MSS substrate, there was a $57.1 \%$ improvement in the $\mathrm{C} / \mathrm{N}$ ratio, reaching a more adequate balance $(\mathrm{C} / \mathrm{N}=11)$ that was mainly due to the DOP contribution in terms of carbon content, whereas a decrease $(22.0 \%)$ in TKN was measured. The TVS/TS and SCOD/TCOD ratios also increased by $3 \%$ and $30 \%$, respectively, indicating significant availability of organic matter for the anaerobic co-digestion process. The blend of 5\% (v/v) DOP and MSS ensured $89 \%$ TVS/TS content in the feed stream. On the other hand, as expected, there was a higher amount of TPhs (around 4.5 times) due to the addition of DOP to the MSS.

As far as AD runs were concerned, the digestates obtained showed a reduction of $18 \%$ in TVS if compared with the values of the feed stream (MSS); it is important to note that this value was enhanced up to $27 \%$ in AcoD runs with DOP as the co-substrate. This implies that almost twice the TVS content is biodegraded when DOP is added to the feed blend.

Another important aspect is that TCOD biodegradability was enhanced by $37.3 \%$ when the process was performed under the AcoD regime. The reduction of TCOD in AD experiments was $13 \%$, whereas it achieved up to $43 \%$ in AcoD, representing a twofold increase in this best scenario. Moreover, with regard to
TPhs concentration, there was an increase of $86 \%$ in removal under the AcoD regime.

The effect on the performance and stability of the MSS anaerobic co-digestion process when DOP is incorporated as a co-substrate is summarised in Table 3.

As can be observed from Table 3, the average daily GPR during the proposed anaerobic co-digestion regime rose as high as $0.39 \pm 0.11 \mathrm{~L} \mathrm{~L}^{-1} \mathrm{~d}^{-1}$, which implied a significant increase, equal to $39.3 \%$, when compared with the $\mathrm{AD}$ operational phase fed with $\mathrm{MSS}$ as a mono-substrate $\left(\mathrm{GPR}_{\mathrm{AD}}=0.28 \pm 0.10 \mathrm{~L}\right.$ $\left.\mathrm{L}^{-1} \mathrm{~d}^{-1}\right)$. Furthermore, in terms of SMP $\left(\mathrm{L} \mathrm{CH}_{4} \mathrm{~g}_{\mathrm{TVs}}{ }^{-1}\right)$ and MPR $\left(\mathrm{L}_{\mathrm{CH} 4} \mathrm{~L}^{-1} \mathrm{~d}^{-1}\right)$, the blend of MSS and 5\% (v/v) DOP provided considerable enhancements, equivalent to $40 \%$ and $37 \%$, respectively.

It is important to highlight that the GPR value attained in the proposed co-digestion process of mixed MSS and DOP is three times higher than that obtained by Serrano et al. $(2017,2019)$ for high-temperature thermally treated OP. Moreover, research developed by Pellera and Gidarakos (2017) using three-phase OP and inoculum from mesophilic anaerobic sludge digestion achieved SMP in a range 1.7 times lower than the yield obtained in this research.

Figure 2 shows the GPR and MPR for AD (a) and AcoD (b). Figure 2(b) includes the AcoD acclimatisation period (see section Material and Methods). It can be seen that the system responds 


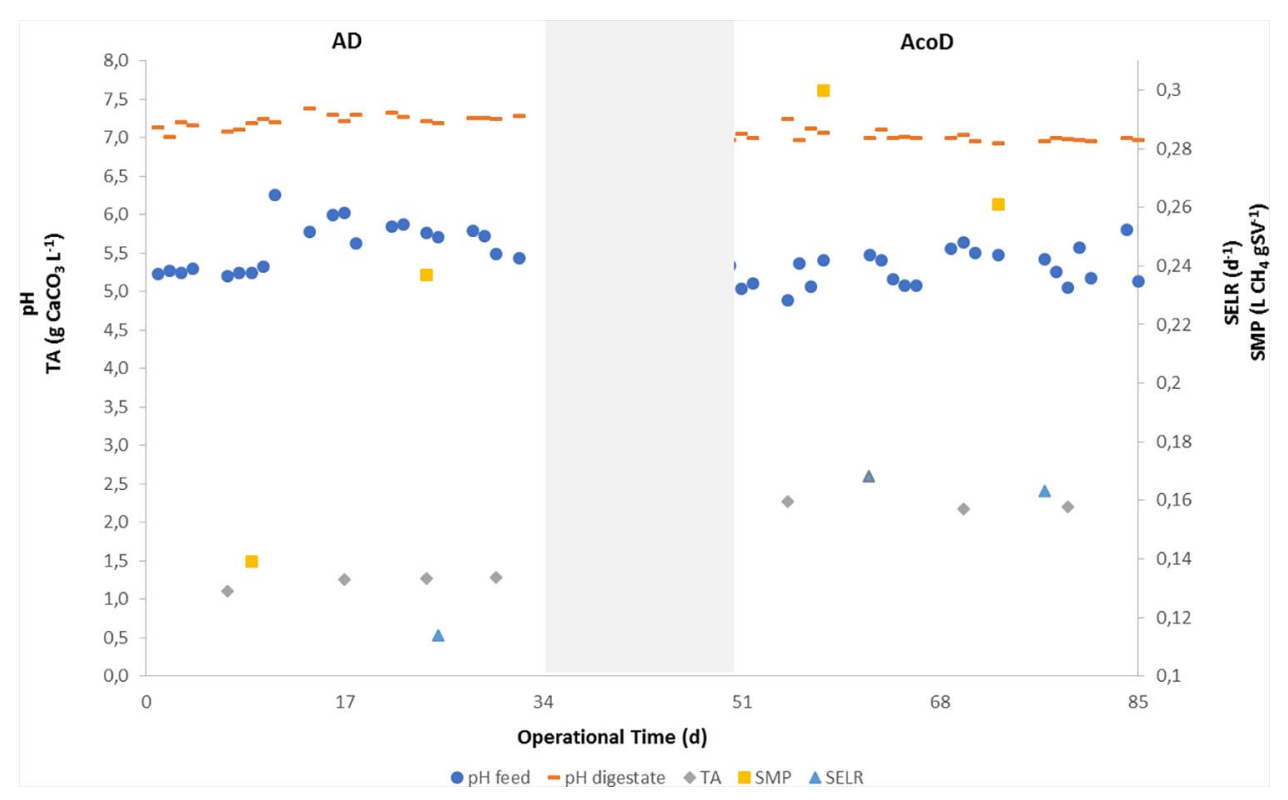

Figure 3. Process stability and performance $(\mathrm{pH}$ of feed and digestate, total alkalinity, specific methane production and specific energy loading rate) in the anaerobic digestion and anaerobic co-digestion trials. The shaded area corresponds to the period needed to acclimatise to anaerobic co-digestion.

AD: anaerobic digestion; AcoD: anaerobic co-digestion; TA: total alkalinity; SMP: specific methane production; SELR: specific energy loading rate.

well to famine periods, because during non-feeding days (data points with a yellow solid line around the marker) there is still biogas production, and production increases when feeding takes place. It should be mentioned that during the first HRT of AD there was a clogging event on the 11th day and that days 12-16 correspond to a weekend followed by bank holidays. Testing reactor performance under these circumstances can give an idea of how the process will perform under real scale conditions.

As can be observed in Figure 2(b), the microbial consortia in the bioreactor were not only able to tolerate the addition of DOP to the MSS, they also responded positively and were able to adapt in a stable way to this new co-substrate. The system was not affected by the phenol concentration introduced by the addition of DOP. This can be seen by the enhancement of bioconversion observed when the shift to the co-digestion process took place (Figure 2(b)), corroborated by the increase in GPR and MPR yields $(\sim 40 \%)$ during various subsequent HRTs if compared with the mono-digestion phase (up to day 34 ).

In addition, the stability patterns of the $\mathrm{AD}$ and $\mathrm{AcoD}$ processes are supported by the data shown in Figure 3, in which key physico-chemical parameters with regard to the bioreactor performance during operation are reported: the $\mathrm{pH}$ of the feed stream and of the digestate, the TA of the digestate, the SMP $\left(\mathrm{LCH}_{4}\right.$ $\mathrm{g}_{\mathrm{TVS}}{ }^{-1}$ ) and the SELR of the system.

As can be noted in Figure 3, a major buffer capacity was attained in the bioreactor when DOP was added as a co-substrate, supported by an increase in and stabilisation of TA values when the shift from AD of MSS to AcoD with DOP was made (Athanasoulia et al., 2012; Maragkaki et al., 2017). TA values for the AcoD trial were very similar to those reported by Serrano et al. (2019) for the same OLR range in a mesophilic CSTR, indicating process stability during the AcoD process. This was also supported by the narrow and stable $\mathrm{pH}$ values measured in the digestate during the whole AcoD phase $(7.02 \pm 0.07)$.

Furthermore, calculation of SELR during AD and AcoD trials allowed comparison of system stability. As mentioned in Materials and Methods section SELR expresses the rate of the methanogenic bioconversion into biogas/biomethane. According to Evans et al. (2016), SELR should be kept below $0.4 \mathrm{~d}^{-1}$. If this capacity is exceeded, the digester might become unstable due to the rate of acidogenesis outpacing the rate of methanogenesis. Values higher than $0.4 \mathrm{~d}^{-1}$ indicate instability among the microbial consortia biomass and with regard to loading the feed mixture. As can be seen from Table 3 and Figure 3, system SELR was maintained at $0.122 \pm 0.02 \mathrm{~d}^{-1}$ during AD of MSS as a monosubstrate (reference scenario), and $0.177 \pm 0.03 \mathrm{~d}^{-1}$ during the AcoD phase of MSS with the addition of $5 \%(\mathrm{v} / \mathrm{v})$ DOP, indicating better buffer capacity and stability in the bioreactor. The fact that during AcoD the SELR was less than the half of the advisable maximum value $\left(0.4 \mathrm{~d}^{-1}\right)$ suggests that the DOP quantity in the feed mixture may be increased to $10 \%$ without risk of digester instability or failure.

The results achieved in this study can contribute to overcome the main challenges posed by the sewage sludge anaerobic digestion process, that is, improvement in biodegradability and enhancement of the methane yield. In fact, finding suitable cosubstrates and optimum operating conditions are among the major challenges for biogas plants (Orfanoudaki et al., 2019; Siddique and Wahid, 2018). The type and structure of substrates together with their biodegradability are the key factors for methane production (Hagos et al., 2017). To overcome these barriers, the introduction of a co-substrate such as DOP with a $\mathrm{C} / \mathrm{N}$ and a 
SCOD/TCOD in the order of 6 and 1.3 times higher than that of MSS, respectively, would help enhance biomethane production. In the present work, co-digestion of DOP improved CSTR performance and enabled it to operate at a higher OLR. The codigestion regime utilising MSS with added DOP ensured improved nutrient balance and process stabilisation, thus increasing biomethane yield (Hagos et al., 2017; Shrestha et al., 2017).

\section{Benefits of changing from mono- digestion to co-digestion for electric energy production}

The specific $\Delta E p\left(\mathrm{kWh} / \mathrm{kg}_{\text {TVS }}\right)$ resulting from changing to an AcoD regime was calculated as described in Materials and Methods section, using the biogas and biomethane yield obtained (Table 3 ).

$$
\Delta E_{p}=\mathrm{E}_{\mathrm{P}}(\mathrm{AcoD})-\mathrm{E}_{\mathrm{P}}(\mathrm{AD})=0.774 \mathrm{kWh} \mathrm{kg}_{\mathrm{TVS}}{ }^{-1}
$$

This result can be applied to estimate the impact of changing to the proposed AcoD process at real industrial scale in a WWTP. For this, a standard WWTP serving approximately 100,000 inhabitants was considered in which an $\mathrm{AD}$ bioreactor with $1800 \mathrm{~m}^{3}$ of active volume was implemented.

The following assumptions were considered:

1. The sludge from PS is thickened and homogenised with WAS, previously thickened by dissolved air flotation. The MSS has an average proportion of 40\% PS:60\% WAS (v/v);

2. The average HRT is 17 days;

3. A medium-sized two-phase olive oil mill processes 2000 3000 mtons of olives per year;

4. The ratio of olive mtons to DOP mtons is 5:4 (Lama et al., 2017; Serrano et al., 2019).

Considering the OLR previously established, that is $0.90 \mathrm{~kg}_{\mathrm{TVS}}$ $\mathrm{m}^{-3}$ reactor $\mathrm{d}^{-1}$ for $\mathrm{AD}$ and $0.94 \mathrm{~kg}_{\mathrm{TVS}} \mathrm{m}^{-3}$ reactor $\mathrm{d}^{-1}$ for AcoD, adopting AcoD leads to an improvement of $0.04 \mathrm{~kg}_{\mathrm{TVS}} \mathrm{m}^{-3}$ reactor $\mathrm{d}^{-1}$. Therefore, for the $1800 \mathrm{~m}^{3}$ bioreactor mentioned in the assumptions there is an extra daily loading of $72 \mathrm{~kg}$ of TVS. Once the $\Delta E p$ is $0.774 \mathrm{kWh} \mathrm{kg} \mathrm{TVs}^{-1}$, this would result in a daily surplus of $55.69 \mathrm{kWh}$, which corresponds to $20,328.6 \mathrm{kWh} \mathrm{year}^{-1}$. If the price of electricity is considered to be $€ 0.162$ per $\mathrm{kWh}$, the annual saving would be $€ 3293.23$.

As can be observed from the results obtained, the surplus of electric energy production ensured by the introduction of only $5 \%$ DOP indicates that its inclusion in the treatment is a promising strategy. The proposed process could result in not only positive environmental impacts but also provide a source of renewable energy that would reduce the specific energy consumption in WWTPs.

A smart and 'green' solution is proposed here for the management of both OP produced in olive mills and MSS generated in WWTPs. On the one hand, the age-old olive oil industry is concerned about making the whole process environmentally friendly, and this implies that the treatment and exploitation of the residues produced in the mills should be done in a technically feasible, environmentally clean and economically efficient manner. On the other hand, WWTPs face the challenge of improving their sustainability in terms of their carbon footprint and effecting a transition to greener forms of energy in the framework of the circular economy.

The results obtained here in relation to an improvement in system performance with regard to biomethane yield when MSS is co-digested with DOP, as compared with mono-digestion of MSS, are rather promising. The introduction of this readily available by-product as a co-substrate in the anaerobic digestion of MSS could be a key factor for the sustainability of both sectors in the next few years.

\section{Conclusions}

In this research work, the impact on anaerobic digestion performance when DOP is added to MSS is considered. The aim was to address the challenge of improving sustainability in terms of carbon footprint and a greener form of energy in the framework of the circular economy for both WWTPs and olive mills, especially in those regions that produce olive oil.

When $5 \%(\mathrm{v} / \mathrm{v})$ DOP co-substrate is added to MSS, a $4.4 \%$ improvement in the OLR as well as a $57 \%$ improvement in the $\mathrm{C} / \mathrm{N}$ ratio was achieved by the system. Moreover, the bioreactor performance was not negatively affected by the concentration of phenols introduced by the addition of DOP. The results obtained confirm not only a significant improvement in terms of biomethane production yield, but also the enhancement of system stability during the co-digestion of MSS and DOP, as compared with mono-digestion of MSS. The shift from a mono-digestion regime to a co-digestion one led to an increase in TCOD biodegradation of 1.4 times in the same HRT (HRT=17 days).

Furthermore, the average daily GPR, SMP and MPR of the system could be successfully increased by $39 \%, 40 \%$ and $37 \%$, respectively, and this was ensured during three consecutive HRTs. This could allow a surplus of electric energy in terms of $20,328.6 \mathrm{kWh}$ year $^{-1}$. The proposed process could not only have a positive environmental impact but could also provide a source of renewable energy that would serve to reduce the specific energy consumption in WWTPs.

The overall results obtained, indicating an electric energy surplus from the co-digestion of DOP and MSS, constitute a promising alternative for both OP from olive mills and MSS from WWTPs in terms of biowaste management in the framework of a transition to greener energy and economy decarbonisation, a key factor for the sustainability of both sectors in the near future.

\section{Acknowledgements}

Spanish Ministry of Economy and Competitiveness is acknowledged for funding project CTM2014-61105-JIN, through which two-phase olive pomace from Spanish olive mills was partially dephenolized to obtain added-value antioxidants, after which partially dephenolized olive pomace was subjected to energetic valorization through anaerobic 
co-digestion in Lisbon. We thank this project also for enabling and financing the research stay of one of the co-authors (Javier M. OchandoPulido) in the ISA (University of Lisbon) during which the research was carried out. We also thank both University of Lisbon and University of Granada for billateral agrreement enabling this scientific collaboration.

\section{Declaration of conflicting interests}

The authors have no conflicts of interest to declare.

\section{Funding}

The authors disclosed receipt of the following financial support for the research, authorship, and/or publication of this article: This work is funded by national funds through FCT -Fundação para a Ciência e a Tecnologia, I.P., in the scope of the project Linking Landscape, Environment, Agriculture And Food Research Centre Ref. UIDB/04129/2020.

\section{ORCID iD}

Rita Fragoso (iD https://orcid.org/0000-0003-2957-7340

\section{References}

Akar T, Tosun I, Kaynak Z, et al. (2009) An attractive agro-industrial byproduct in environmental cleanup: Dye biosorption potential of untreated olive pomace. Journal of Hazardous Materials 166: 1217-1225.

Alagoz BA, Yenigun O and Erdinçler A (2015) Enhancement of anaerobic digestion efficiency of wastewater sludge and olive waste: Synergistic effect of co-digestion and ultrasonic/microwave sludge pre-treatment. Waste Management 46: 182-188.

Athanasoulia E, Melidis P and Aivasidis A (2012) Optimization of biogas production from waste activated sludge through serial digestion. Renewable Energy 47: 147-151.

Baccar R, Bouzid J, Feki M, et al. (2009) Preparation of activated carbon from Tunisian olive-waste cakes and its application for adsorption of heavy metal ions. Journal of Hazardous Materials 162: 1522-1529.

Baird R and Bridgewater L (eds) (2017) Standard methods for the examination of water and wastewater, 23rd edn. Washington, DC: American Public Health Association

Battista F, Fino D, Erriquens F, et al. (2015) Scaled-up experimental biogas production from two agro-food waste mixtures having high inhibitory compound concentrations. Renewable Energy 81: 71-77.

Battista F, Ruggeri B, Fino D, et al. (2013) Toward the scale-up of agro-food feed mixture for biogas production. Journal of Environmental Chemical Engineering 1: 1223-1230.

Bouzid J, Elouear Z, Ksibi M, et al. (2008) A study on removal characteristics of copper from aqueous solution by sewage sludge and pomace ashes. Journal of Hazardous Materials 152: 838-845.

Camarillo R and Rincón J (2012) Effect of inhibitory compounds on the twophase anaerobic digestion performance of diluted wastewaters from the alimentary industry. Chemical Engineering Journal 193-194: 68-76.

Caputo AC, Scacchia F and Pelagagge PM (2003) Disposal of byproducts in olive oil industry: waste-to-energy solutions. Applied Thermal Engineering 23:197-214.

Cuetos MJ, Fernández C, Gómez X, et al. (2011) Anaerobic co-digestion of swine manure with energy crop residues. Biotechnology and Bioprocess Engineering 16: 1044-1052.

Dermeche S, Nadour M, Larroche C, et al. (2013) Olive mill wastes: Biochemical characterization and valorization strategies. Process Biochemistry 48: 1532-1552.

Espadas-Aldana GE, Vialle C, Belaud JP, et al. (2019) Analysis and trends for Life Cycle Assessment of olive oil production. Sustainable Production and Consumption 19: 216-230.

Evans P, Vandenburgh S, Miller T, et al. (2016) Renewable Energy Production from DoD Installation Solid Wastes by Anaerobic Digestion. Final report. Arlington, VA: Environmental Security Technology Certification Program and Water Environmental Research Foundation. Available at:
https://www.serdp-estcp.org/Program-Areas/Environmental-Restoration/ ER-200933 (accessed on 12 January 2020).

FAO (2019) FAOSTAT data. http://www.fao.org/faostat/en/\#data/QD (accessed 20 December 2019).

Fezzani B and Cheikh RB (2010) Two-phase anaerobic co-digestion of olive mill wastes in semi-continuous digesters at mesophilic temperature. Bioresource Technology 101: 1628-1634.

Greenberg AE, Clesceri LS and Eaton AD (2005) Standard Methods for the Examination of Water and Wastewater, 22nd ed. Washington, DC: American Public Health Association.

Gunay A and Karadag D (2015) Recent development in the anaerobic digestion of olive mill effluents. Process Biochemistry 50: 1893-1903.

Haddadin MS, Haddadin J, Arabiyat OI, et al. (2009) Biological conversion of olive pomace into compost by using Trichoderma harzianum and Phanerochaete chrysosporium. Bioresource Technology 100: 4773-4782.

Hagos K, Zong J, Li D, et al. (2017) Anaerobic co-digestion process for biogas production: Progress, challenges and perspectives. Renewable and Sustainable Energy Reviews 76: 1485-1496.

IOC (2018) World olive oil figures/EU olive oil figure. Available at: https:// www.internationaloliveoil.org/what-we-do/economic-affairs-promotionunit/\#figures (accessed 20 December 2019).

Kathijotes N (2016) Blue technology - the water-energy interrelationship. Renewable energies and nutrient recovery. Asia-Pacific Journal of Science and Technology 21: 102-109.

Lama D, Borja R and Rincón B (2017) Performance evaluation and substrate removal kinetics in the semi-continuous anaerobic digestion of thermally pre-treated two-phase olive pomace or 'Alperujo'. Process Safety and Environmental Protection 105: 288-296.

Li Y, Chen Y and Wu J (2019) Enhancement of methane production in anaerobic digestion process: A review. Applied Energy 240: 120-137.

Malkoc E, Nuhoglu Y and Dundar M (2006) Adsorption of chromium (VI) on pomace - an olive oil industry waste: Batch and column studies. Journal of Hazardous Materials 138: 142-151.

Maragkaki AE, Fountoulakis M, Gypakis A, et al. (2017) Pilot-scale anaerobic co-digestion of sewage sludge with agro-industrial by-products for increased biogas production of existing digesters at wastewater treatment plants. Waste Management 59: 362-370.

Muscolo A, Papalia T, Settineri G, et al. (2019) Three different methods for turning olive pomace in resource: Benefits of the end products for agricultural purpose. Science of the Total Environment 662: 1-7.

Ochando-Pulido JM, González-Hernández R, and Martinez-Ferez A (2018) On the effect of the operating parameters for two-phase olive oil washing wastewater combined phenolic compounds recovery and reclamation by novel ion exchange resins. Separation and Purification Technology 195: 50-59.

Orfanoudaki A, Makridakis G and Maragkaki A (2019) Anaerobic co-digestion of pig manure and spent coffee grounds for enhanced biogas production. Waste and Biomass Valorization 11: 4613-4620.

Orive M, Cebrián M and Zufía J (2016) Techno-economic anaerobic codigestion feasibility study for two-phase olive oil mill pomace and pig slurry. Renewable Energy 97: 532-540.

Pellera FM and Gidarakos E (2017) Anaerobic digestion of solid agroindustrial waste in semi-continuous mode: Evaluation of mono-digestion and co-digestion systems. Waste Management 68: 103-119.

Pinto N, Carvalho A, Pacheco J, et al. (2016) Study of different ratios of primary and waste activated sludges to enhance the methane yield. Water and Environment Journal 30: 203-210.

Raheem A, Sikarwar V, He J, et al. (2018) Opportunities and challenges in sustainable treatment and resource reuse of sewage sludge: A review. Chemical Engineering Journal 337: 616-641.

Rincón B, Bujalance L, Fermoso FG, et al. (2013) Biochemical methane potential of two-phase olive mill solid waste: Influence of thermal pretreatment on the process kinetics. Bioresource Technology 140: 249-255.

Rodríguez G, Lama A, Rodríguez R, et al. (2008) Olive stone - an attractive source of bioactive and valuable compounds. Bioresource Technology 99: 5261-5269.

Salome R, Cappelletti GM, Malandrino O, et al. (2015) Life cycle assessment in the olive oil sector. In: Notarnicola B, Salomone R, Petti L, et al. (eds) Life Cycle Assessment in the Agri-food Sector. Cham: Springer, 57-121.

Serrano A, Fermoso FG, Alonso-Fariñas B, et al. (2019) Performance evaluation of mesophilic semi-continuous anaerobic digestion of high-temperature thermally pre-treated olive mil solid waste. Waste Management 87 : 250-257. 
Serrano A, Fermoso FG, Rodríguez-Gutierrez G, et al. (2017) Biomethanization of olive mill solid waste after phenols recovery through low-temperature thermal pre-treatment. Waste Management 61: 229-235.

Shrestha S, Fonoll X, Khanal SK, et al. (2017) Biological strategies for enhanced hydrolysis of lignocellulosic biomass during anaerobic digestion: Current status and future perspectives. Bioresource Technology 245: $1245-1257$.

Siciliano A, Stillitano MA and De Rosa S (2016) Biogas production from wet olive mill wastes pre-treated with hydrogen peroxide in alkaline conditions. Renewable Energy 85: 903-916.

Siddique MNI and Wahid ZA (2018) Achievements and perspectives of anaerobic co-digestion: A review. Journal of Cleaner Production 194: 359-371.

Singh A and Basak P (2018) Economic and environmental evaluation of municipal solid waste management system using industrial ecology approach: Evidence from India. Journal of Cleaner Production 195: 10-20.

Stasinakis A, Elia I, Petalas AV, et al. (2008) Removal of total phenols from olive-mill wastewater using an agricultural by-product, olive pomace. Journal of Hazardous Materials 160: 408-413.
Stoyanova E, Lundaa T, Bochmann G, et al. (2017) Overcoming the bottlenecks of anaerobic digestion of olive mill solid waste by two-stage fermentation. Environmental Technology 38: 394-405.

Tekin AR and Coşkun Dalgıç A (2000) Biogas production from olive pomace. Resources, Conservation and Recycling 30: 301-313.

Von Mitzlaff K (1988) Engines for Biogas. Eschborn, Germany: GATE. Available at: https://biogas.ifas.ufl.edu/ad_development/documents/ Engines\%20for\%20biogas.pdf (accessed on 3 February 2020).

Yang Q, Wu B, Yao F, et al. (2019) Biogas production from anaerobic co-digestion of waste activated sludge: Co-substrates and influencing parameters. Reviews in Environmental Science and Bio/Technology 18: 771-793.

Zhang C, Su H, Baeyens J, et al. (2014) Reviewing the anaerobic digestion of food waste for biogas production. Renewable and Sustainable Energy Reviews 38: 383-392.

Zhang J, Li W, Lee J, et al. (2017) Enhancement of biogas production in anaerobic co-digestion of food waste and waste activated sludge by biological co-biowaste. Energy 137: 479-486. 